\title{
Protection against experimental salmonellosis in mice and sheep by immunisation with aromatic-dependent Salmonella typhimurium
}

\author{
T.K.S. MUKKUR, G. H. McDOWELL,* B. A. D. STOCKER† and A. K. LASCELLES \\ CSIRO Division of Animal Health, McMaster Laboratory, Glebe, NSW 2037, Australia, " Dairying Research Unit, \\ Department of Animal Husbandry, University of Sydney, Camden, NSW 2570, Australia and tDepartment of \\ Medical Microbiology, Stanford University School of Medicine, Stanford, CA 94305, USA
}

\begin{abstract}
Summary. Mice immunised by the oral or intraperitoneal route with a live aromaticdependent strain of Salmonella typhimurium exhibited significantly less protection against oral challenge with 50 LD50 of an ovine isolate of S. typhimurium (12313) than when a bovine isolate with the same $O$ antigens and phage-type as strain 12313 was used as the challenge organism. When challenged with 10 LD50, however, protection against both strains was significantly better than that obtained when mice were vaccinated with killed vaccines (heat-killed, acetone-killed or irradiated) even when the antigenic mass of the killed vaccine was increased by up to 500 -fold in an attempt to compensate for the expected limited multiplication of the mutant organism. Sheep immunised with the live mutant strain by either the intramuscular or oral route were protected against oral challenge with the virulent ovine isolate of $S$. typhimurium; unimmunised sheep died of acute enteritis within 7 days, although there was no evidence of systemic invasion by the challenge organism. After challenge, immunised animals ate more food than the unimmunised controls and suffered only transient, mild diarrhoea. Serum antibody titres against $\mathrm{O}$ and $\mathrm{H}$ antigens measured by direct or antiglobulin tests were significantly higher in sheep immunised by the intramuscular route than in those immunised orally. Sheep in both immunised groups developed skin swellings within 30 min after intradermal inoculation with purified homologous lipopolysaccharide indicating development of immediate-type hypersensitivity, but only those immunised by the intramuscular route showed significant indurated skin swellings characteristic of delayed-type hypersensitivity 48 and $72 \mathrm{~h}$ post-inoculation. Thus it appears that protection against salmonellosis in sheep immunised by the intramuscular or the oral route may involve different mechanisms.
\end{abstract}

\section{Introduction}

Salmonellosis of food producing animals is a serious public health hazard. It is also an economically important disease of sheep, causing infections and deaths in intensive husbandry conditions, which can result in huge economic losses under stressful conditions such as those encountered during the shipping of animals. Among the various serotypes of Salmonella isolated from cases of clinical salmonellosis in sheep in Australia, $S$. typhimurium usually predominates (Murray, 1984).

Numerous attempts have been made to protect mice and ruminant animals against salmonellosis with killed, subunit or live vaccines. Whereas the

Received 22 Oct 1985 : revised version accepted 21 Jun. 1986. use of non-living vaccines has been reported by some investigators to confer protection against experimental salmonellosis (Eisenstein and Angerman, 1978; Kuusi et al., 1979, 1981 ; Svenson et al., 1979; Tato et al., 1979; Angerman and Eisenstein, 1980; Aitken et al., 1982; Desiderio and Campbell, 1985), others found that live vaccines were superior to killed vaccines in protecting mice and calves against experimental challenge infections with virulent salmonellae (Mitsuhashi et al., 1958; Ushiba et al., 1959; Smith, 1965; Collins et al., 1966; Germanier, 1972; Ivanoff et al., 1980; Robertsson et al., 1983; Smith et al., 1984). A galE mutant characterised by a block in the enzyme uridine diphosphate-4-epimerase has been used in immunisation trials in ruminants. Calves immunised with this mutant were protected against 
experimental salmonellosis (Wray et al., 1977), although the protection reported in sheep was not as good (Jelinek et al., 1982). Although reversion of the galE mutant to wild-type in vivo has not been reported (Germanier and Furer, 1971), the frequency of secondary mutations in vitro is significantly higher than that reported for the aromaticdependent salmonella mutant (Hoiseth and Stocker, 1981). One such strain, SL1479, was derived from a virulent bovine isolate of $S$. typhimurium and constructed to have a complete, non-reverting defect in the common aromatic biosynthetic pathway, caused by a transposongenerated deletion or deletion-inversion mutation of gene aroA (Hoiseth and Stocker, 1981). Such mutant strains were shown to be avirulent and induced a highly effective immunity in mice (Hoiseth and Stocker, 1981) and calves (Robertsson et al., 1983; Smith et al., 1984).

The aims of the present investigation were, first, to compare the immunising efficacy of the live salmonella mutant SL1479 in mice against oral challenge with a virulent bovine or ovine isolate of the same phage type, and, second, to compare the immunising efficiency of live and killed vaccines prepared from strain SL1479 against challenge by the oral rather than the intraperitoneal route which has been used in most previous investigations. Although SL1479 has been reported to protect calves against challenge by the oral (Robertsson $e t$ al., 1983) or intramuscular routes (Smith et al., 1984), a comparison of the efficacy of these routes of immunisation cannot be made because of differences in the number of vaccine doses, presence of adjuvant, and the regimes of immunisation used. The third aim of this investigation, was to compare the clinical and immunological responses, and protection against experimental salmonellosis in sheep immunised by either the intramuscular or oral routes employing comparable regimes of immunisation.

\section{Materials and methods}

\section{Experimental animals}

Specific pathogen-free, Balb/c female mice (18-22g) aged $c$. 8 weeks and Merino wether sheep, aged 9-12 months were obtained from the CSIRO McMaster Farm, Badgery's Creek, NSW. Depending on the immunisation schedule, groups of 20-30 mice were used and were boxed in groups not exceeding 15 mice per cage post-vaccination and 10 mice per cage post-challenge. Mice were vaccinated at $c .8$ weeks of age and mice aged $c .9$ weeks were used for determination of the $50 \%$ lethal dose (LD50).
For experimental challenge infections, sheep were isolated and housed in separate pens with raised floors at the University of Sydney, Camden, NSW.

\section{Bacterial strains and vaccine preparation}

The auxotrophic mutant of $S$. typhimurium (strain SL1479; O antigens 1, 4, 12; phage-type 193) used as the vaccine was derived from $S$. typhimurium UCD 108-11, originally isolated from a calf that died of enteritis (Smith et al., 1984). The $S$. typhimurium strains used for experimental challenge were a bovine isolate 7328 (O antigens 4, 5, 12; phage-type 9) and an ovine isolate, 12313 (O antigens 4, 5, 12; phage-type 9). These two strains were obtained from the Salmonella Reference Centre, Institute of Medical and Veterinary Science, Adelaide, South Australia, through the courtesy of Mr C. Murray.

The live vaccine was prepared by growing strain SL1479 in Brain Heart Infusion Broth (Oxoid) in shaking flasks at $37^{\circ} \mathrm{C}$ for $18 \mathrm{~h}$. After centrifugation at $12350 \mathrm{~g}$ for $30 \mathrm{~min}$ the pellet was washed three times in phosphatebuffered saline (PBS) before final resuspension in PBS. Organisms in the vaccine were counted by the agar spread plate count technique. The killed vaccines were prepared by heating the washed suspensions of the live mutant SL1479 $\left(10^{10}\right.$ organism $\left./ \mathrm{ml}\right)$ at $100^{\circ} \mathrm{C}$ for $1 \mathrm{~h}$, or irradiation with $10^{6}$ rads, or acetone treatment (Landy, 1953); these are referred to as heat-killed, irradiated and acetone-killed cells or vaccines respectively. Fresh vaccine preparations were used for every experiment and appropriately diluted before use.

\section{Determination of the LD50 in mice}

Mice were infected by gavage with varying numbers of the bovine (7328) or ovine (12313) isolates of virulent $S$. typhimurium and mortalities recorded for 15 days postinfection. The LD50 doses $( \pm \mathrm{SE})$ calculated according to Litchfield and Wilcoxon (1949) were $(7 \cdot 2 \pm 2 \cdot 2) \times 10^{4}$ and $(5 \cdot 0 \pm 2 \cdot 2) \times 10^{5}$ for the bovine and ovine isolates respectively.

\section{Extraction of lipopolysaccharide (LPS)}

The hot phenol-water extraction procedure (Westphal and Jann, 1965) was used for extracting LPS from the formalin-killed Salmonella mutant SL1479. Highly-purified LPS was obtained by preparative ultracentrifugation as described by Lindberg and Holme (1972).

Experimental reproduction of clinical salmonellosis in sheep

Sixteen Merino wethers were infected orally with varying numbers of the ovine isolate of $S$. typhimurium (12313) enclosed in gelatin capsules $\left(10^{7}\right.$ organisms were given to two sheep, $10^{8}$ organisms to three sheep, $10^{9}$ organisms to three sheep, $10^{10}$ organisms to three sheep, $10^{11}$ organisms to three sheep, $10^{12}$ organisms to two sheep). Gelatin capsules were used for enclosing the 
challenge organisms to avoid complications due to closure of the oesophageal groove (Prichard and Hennessy, 1981). These animals were monitored for a rise in body temperature, development of diarrhoea and faecal excretion of the challenge organism. Sheep that died during the course of infection were necropsied and the surviving animals were killed 15 days post-challenge. Various tissues including liver, spleen, ileal and caecal lymph nodes, bile and blood were plated directly on Xylose Lysine Deoxycholate (XLD) agar (Oxoid) and also cultured on cysteine-mannitol-selenite enrichment media.

\section{Experimental design of immunisation and challenge studies}

Mice. Groups of mice (20-30 per group) were immunised with either the live or killed mutant strain, SL1479, by the intraperitoneal (ip) or oral route and challenged 3 or 4 weeks later by oral administration of 50 LD50 or 10 LD50 of the bovine (7328) or ovine isolate (12313) of $S$. typhimurium. Unvaccinated mice (20-24 per group) were included in all challenge experiments as controls. Any mice in which there was any doubt about the precision of the vaccine or challenge delivery were culled from the experiment.

Sheep. Three groups each of five Merino wethers were used. Sheep in group 1 were immunised with the live $S$. typhimurium mutant SL1479, by the intramuscular (im) route, and those in group II by oral administration of the live-vaccine organisms in gelatin capsules. Animals in group III served as unimmunised controls. Sheep in groups I and II received three vaccinations at weekly intervals $\left(10^{8}, 10^{10}\right.$ and $10^{10}$ organisms respectively). Twenty-one days later all animals were challenged with $1 \times 10^{9}$ of the ovine isolate of S. typhimurium (12313) administered in gelatin capsules. An additional group of 4 sheep was immunised with the heat-killed mutant strain, SL1479, by the im route using the immunisation regimen identical to that for sheep in group I. Sheep in this group were used only for comparative assessment of immunological parameters including agglutination titres and skin reactions.

The experiment was terminated 20 days after the challenge infection. Excretion of the challenge strain in faeces was monitored by enrichment culture in mannitolselenite broth containing cysteine followed by plating out on XLD media. Each animal was sampled on days one to 8 and on days 11,14 and 20 after challenge. Sheep were considered to be free of infection when four consecutive faecal cultures were negative. Blood cultures were also monitored from days $2-6$ post-challenge. The surviving sheep were killed with a captive bolt and a necropsy performed; various organs including liver, spleen, ileal and caecal lymph nodes, bile, segments of duodenal, ileal and caecal wall, and the associated intestinal contents were cultured for the presence of the challenge strain by direct plating on the XLD medium and also following enrichment in mannitol-selenite broth containing cysteine.
Clinical parameters. Rectal temperatures, total white blood cell (WBC) count and the differential WBC counts were determined pre-challenge and on days 1-8, 11, 14 and 20 days post-challenge with virulent $S$. typhimurium. Animals were weighed before challenge and at weekly intervals post-challenge. Food intake was assessed every $24 \mathrm{~h}$ during the first 8 days and also on days 11,14 and 20 days post-challenge. The extent of diarrhoea in challenged sheep in all groups was estimated using the arbitrary scoring system described below: $\mathrm{O}=$ normal hard pellets with distinct conformation; $1=$ pellets soft but pellet conformation still distinct; $2=$ pellets soft and pellet conformation changed so as to result in partial coalescing of multiple pellets; $3=$ soft faecal mass without discrete pellets; $4=$ faecal mass a viscous paste; $5=$ thin faecal paste, significantly reduced solid matter; $6=$ watery diarrhoea with mucus, occasional blood stains and shreds of mucous membranes.

\section{Immunological parameters}

Agglutination tests were performed in microtitration plates by a standard procedure (Campbell et al., 1970). Antigen was prepared from heat-killed mutant organisms $\left(\mathrm{SL} 1479,100^{\circ} \mathrm{C}, 1 \mathrm{~h}\right.$ ) to determine anti-O group-antigen titres, and a formalinised $(0.3 \%$ final concentration) suspension of the same organisms was used for determination of anti-H antigen titres (Campbell et al., 1970). Anti-globulin anti-O and $\mathrm{H}$ titres were determined by a modification of the method of Gel and Coombs (1968) described by Husband and McDowell (1978). Immediate and delayed skin reactions were measured with a Vernier caliper before intradermal injection of $0.05 \mathrm{ml}$ of purified LPS $(100 \mu g)$ prepared from the strain, SL1479, and at $30 \mathrm{~min}, 24,48$ and $72 \mathrm{~h}$ post-inoculation. The thickness of the double skin-fold was assessed one week after the last immunising dose and was represented as the difference between the double skin-fold thickness at the specified times and that measured immediately before intradermal injection.

\section{Statistical analyses}

Student's test was used to determine the significance of differences between mean $\log _{10}$ values for the agglutination titres. $\mathrm{X}^{2}$-square test was used to determine the significance of protection observed in the mouse immunisation and challenge experiments except in tables with zero entries where significance was assessed by Fisher's exact test.

\section{Results}

\section{Mouse experiments}

$S$. typhimurium is considered to be a non-host adapted serotype, and it was of interest to compare the protection afforded by $S$. typhimurium mutant SL1479 (derived from a bovine isolate) against challenge with wild-type bovine or ovine isolates of 
S. typhimurium. Immunised mice exhibited significantly less protection against challenge with the ovine isolate (12313) than with the bovine isolate (7328) even though both challenge strains had similar $\mathrm{O}$ antigens $\left({ }^{-} 1,4^{+}, 5^{+}, 12^{+}\right)$and were both of phage type 9 . At a low challenge dose (10 LD50), however, the protection obtained with the ovine isolate was significant by greater $(\mathrm{p}<0.05)$ than with the killed vaccines (tables I and II). Regardless of the method of inactivation used, however, immunisation with killed $S$. typhimurium strain SL1479, given ip even when the dose was 500 times that of the live mutant, failed to protect mice from challenge (table II). It is also evident (table I) that immunisation with living organisms by either the oral or ip route gave rise to similar levels of protection.

\section{Experimental reproduction of clinical salmonellosis in sheep}

The first experiment was designed to determine an approximate $25 \%$ (LD25) or $50 \%$ (LD50) lethal dose of the ovine isolate of $S$. typhimurium (12313) for sheep and at the same time confirm the manifestations of clinical salmonellosis reported previously (Brown et al., 1976). With the exception of sheep that received $10^{7}$ virulent $S$. typhimurium, all remaining animals developed elevated temperatures $\left(1^{\circ}-2 \cdot 2^{\circ} \mathrm{C}\right)$ and severe diarrhoea by days $4-5$ post-challenge (details not shown). The diarrhoea, which was often blood-stained and contained mucus shreds, persisted until death of the animals on day 6-8 post-challenge. Administration of $10^{7}$ organisms caused no deaths, $10^{8}$ organisms killed 1 of 3 sheep, $10^{9}$ organisms killed 3 of 3 sheep, $10^{10}$ and
$10^{11}$ organisms killed 2 out of 3 sheep, $10^{12}$ organisms killed 2 out of 2 sheep. Using probit analysis, the LD50 and LD25 were estimated to be $6.42 \times 10^{8}\left(95 \%\right.$ confidence interval; $1.27 \times 10^{8}$, $\left.3.25 \times 10^{9}\right)$ and $3.10 \times 10^{7}\left(95 \% \mathrm{CI} ; 2.90 \times 10^{6}\right.$, $3.31 \times 10^{8}$ ) respectively. In none of these animals was the virulent challenge strain of $S$. typhimurium cultivated from liver, spleen, bile or blood with or without enrichment cultures. In only 2 of 16 animals were the organisms recovered from the ileal and caecal lymph nodes. However, the organisms were always recovered from the gut contents, and the ileal and caecal walls by direct plating on XLD agar or after enrichment in cysteine-mannitol selenite broth. Therefore, it was apparent that salmonellosis, in this investigation, was characterised by acute enteritis without systemic involvement.

\section{Immunisation experiments}

In view of the failure of killed vaccines to confer protection in our mouse experiments and the poor performance of killed vaccines in calves in general, it was decided to evaluate the immunising efficacy of only the live mutant SL1479 in the sheep experiments in which im (group I) and oral (group II) immunisation was used.

Clinical responses. Immunisation of sheep with the live mutant by either route had no effect except for a temperature rise $\left(0.4-0.8^{\circ} \mathrm{C}\right)$ in 3 of 10 immunised animals on days 2 and 3 after each immunisation. Sheep maintained their appetite and weight during the period of multiple immunisations. After challenge with the virulent organisms, there was an appreciable rise in rectal temperature $\left(0 \cdot 9-2 \cdot 2^{\circ} \mathrm{C}\right)$ during the first $2-3$ days in vaccinated and unvaccinated sheep. In immunised animals,

Table I. Protection of mice immunised with live aromatic-dependent S. typhimurium strain SL1479

\begin{tabular}{|c|c|c|c|c|c|}
\hline \multirow[b]{3}{*}{$\begin{array}{l}\text { Route of } \\
\text { immunisation } \dagger\end{array}$} & \multirow{3}{*}{$\begin{array}{l}\text { Time of challenge } \\
\text { (weeks post- } \\
\text { immunisation) }\end{array}$} & \multicolumn{4}{|c|}{$\begin{array}{l}\text { Number of mice surviving/total number challenged by the oral route with virulent } \\
\text { S. typhimurium, phage type } 9\end{array}$} \\
\hline & & \multicolumn{2}{|c|}{ Bovine isolate 7328} & \multicolumn{2}{|c|}{ Ovine isolate 12313} \\
\hline & & $\begin{array}{l}3.6 \times 10^{6} \mathrm{cfu} \\
(50 \mathrm{LD} 50)\end{array}$ & $\begin{array}{l}7 \cdot 2 \times 10^{5} \mathrm{cfu} \\
(10 \mathrm{LD} 50)\end{array}$ & $\begin{array}{l}2 \cdot 5 \times 10^{7} \mathrm{cfu} \\
(50 \mathrm{LD} 50)\end{array}$ & $\begin{array}{l}5 \times 10^{6} \mathrm{cfu} \\
(10 \mathrm{LD} 50)\end{array}$ \\
\hline Intraperitoneal & 4 & $21 / 24^{a *}$ & $24 / 24^{\mathrm{b} *}$ & $9 / 24^{e}$ & $17 / 24^{\mathrm{f} *}$ \\
\hline Oral & 3 & $20 / 26^{c *}$ & $24 / 24^{d *}$ & $10 / 24^{g}$ & $18 / 24^{\text {h* }}$ \\
\hline Unimmunised & 4 & $0 / 24$ & $0 / 24$ & $0 / 20$ & $0 / 20$ \\
\hline
\end{tabular}

† Mice immunised by the intraperitoneal route received $1 \times 10^{5} \mathrm{cfu}$ whereas those immunised by the oral route received $1 \times 10^{5} \mathrm{cfu}$ on day $0,5 \times 10^{5}$ cfu on day 7 and $4 \times 10^{6}$ cfu on day 14 .

* Significant protection afforded by vaccination: $\mathrm{p}<0.05$ (a vs. $\mathrm{e} ; \mathrm{c}$ vs. $\mathrm{g}$; $\mathrm{f}$ and $\mathrm{h}$ vs. protection obtained with killed vaccines, see table II) and $\mathrm{p}<0.001$ (a, b, c, d, f and h vs. protection obtained with killed vaccines, see table II). 
Table II. Protection of mice immunised intraperitoneally with killed aromatic-dependent $S$. typhimurium strain SL1479

\begin{tabular}{|c|c|c|c|c|c|}
\hline \multirow[b]{3}{*}{ Vaccine and dose } & \multirow{3}{*}{$\begin{array}{l}\text { Time of challenge } \\
\text { (weeks post- } \\
\text { immunisation) }\end{array}$} & \multicolumn{4}{|c|}{$\begin{array}{c}\text { Number of mice surviving/total number challenged by the oral route with } \\
\text { virulent } S . \text { typhimurium phage type } 9\end{array}$} \\
\hline & & \multicolumn{2}{|c|}{ Bovine isolate 7328} & \multicolumn{2}{|c|}{ Ovine isolate 12313} \\
\hline & & $\begin{array}{l}3.6 \times 10^{6} \mathrm{cfu} \\
(50 \mathrm{LD} 50)\end{array}$ & $\begin{array}{l}7 \cdot 2 \times 10^{5} \mathrm{cfu} \\
(10 \mathrm{LD} 50)\end{array}$ & $\begin{array}{l}2 \cdot 5 \times 10^{7} \mathrm{cfu} \\
(50 \mathrm{LD} 50)\end{array}$ & $\begin{array}{l}5 \times 10^{6} \mathrm{cfu} \\
(10 \mathrm{LD} 50)\end{array}$ \\
\hline Heat-killed Cells & 4 & & & & \\
\hline (i) $1 \times 10^{5}$ organisms & & $4 / 24$ & $11 / 28$ & $3 / 22$ & $6 / 23$ \\
\hline (ii) $1 \times 10^{6}$ organisms & & $4 / 22$ & $9 / 25$ & $6 / 25$ & $9 / 24$ \\
\hline (iii) $1 \times 10^{7}$ organisms & & $4 / 22$ & $10 / 28$ & $7 / 26$ & $10 / 29$ \\
\hline (iv) $5 \times 10^{7}$ organisms & & $5 / 24$ & $7 / 26$ & $6 / 23$ & $8 / 28$ \\
\hline (v) Unimmunised & & $0 / 27$ & $0 / 24$ & $0 / 20$ & $0 / 20$ \\
\hline Irradiated Cells & 4 & & & & \\
\hline (i) $1 \times 10^{5}$ organisms & & $6 / 24$ & $10 / 25$ & $4 / 26$ & $9 / 26$ \\
\hline (ii) $1 \times 10^{6}$ organisms & & $4 / 25$ & $9 / 25$ & $5 / 27$ & $10 / 25$ \\
\hline (iii) $1 \times 10^{7}$ organisms & & $3 / 21$ & $9 / 30$ & $2 / 22$ & $4 / 23$ \\
\hline (iv) $5 \times 10^{7}$ organisms & & $7 / 20$ & $9 / 20$ & $4 / 20$ & $6 / 22$ \\
\hline (v) Unimmunised & & $0 / 20$ & $0 / 20$ & $0 / 20$ & $0 / 20$ \\
\hline Acetone-killed Cells & 4 & & & & \\
\hline (i) $1 \times 10^{5}$ organisms & & $1 / 24$ & $7 / 24$ & $0 / 24$ & $3 / 23$ \\
\hline (ii) $1 \times 10^{6}$ organisms & & $5 / 25$ & $10 / 25$ & $3 / 25$ & $7 / 24$ \\
\hline (iii) $5 \times 10^{7}$ organisms & & $4 / 25$ & $8 / 27$ & $4 / 26$ & $7 / 26$ \\
\hline (iv) Unimmunised & & $0 / 20$ & $0 / 20$ & $0 / 23$ & $0 / 23$ \\
\hline
\end{tabular}

rectal temperatures returned to normal by days $5-6$ whereas, in the control group, temperatures continued to rise until shortly before death. There was a significant elevation in the total WBC count in all groups at 2-3 days post-challenge, followed by neutropenia at 5-7 days post-challenge and this was most severe in the control group. Appetite and body weight in the immunised groups did not change appreciably during the 20-day period (data not shown) and only a transient mild-to-moderate diarrhoea (fig. 1) occurred. All animals (5 out of 5) in groups I and II survived challenge; they had relatively minor clinical signs. Although orallyimmunised animals seemed to be slightly more affected on days $6,7,8$ and 11 post-challenge than their im-immunised counterparts, there were no

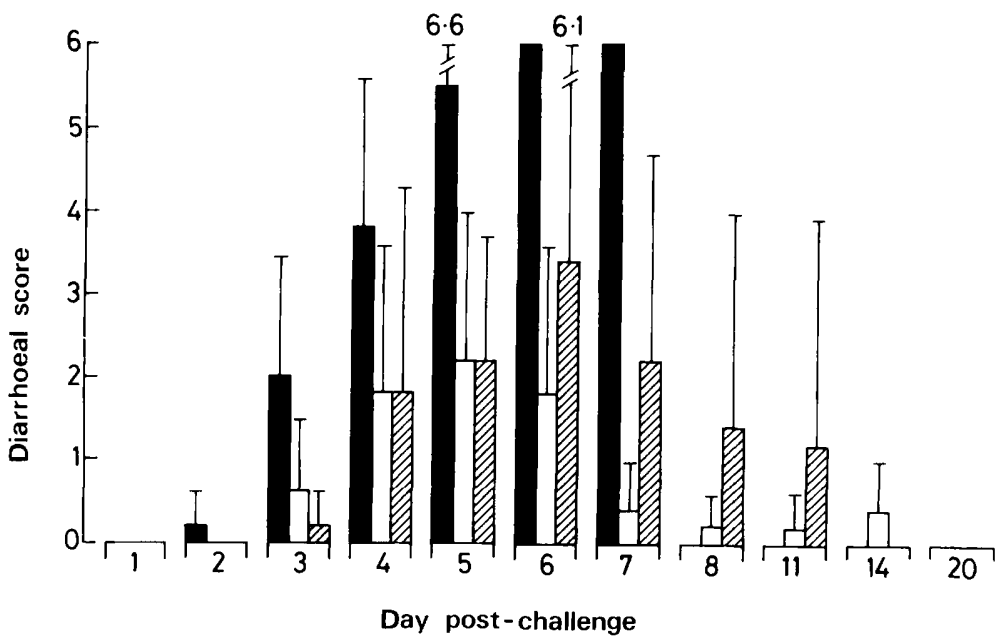

Fig. 1. Diarrohoeal scores of immunised and control sheep after challenge with virulent $S$. typhimurium. Histograms represent mean values + SEM (bars); $\square$ unimmunised; $\square$ live, im; שlive oral. 
statistically significant differences in any of the clinical parameters monitored. At termination of the experiment, the challenge strain of S. typhimurium was recovered from the faeces of 3 of 5 immunised sheep. In contrast, the unvaccinated control animals (Group III) quickly became seriously ill with profuse diarrhoea (fig. 1), dehydration and weight loss and all died within 7 days after challenge.

Antibody responses. The results for anti-O and anti- $\mathrm{H}$ agglutination titres, both direct and with antiglobulin are presented in figs. 2A-D. In animals immunised with the live mutant strain SL1479, there was a difference in the response between orally- and im-immunised animals; there were large increases in titres after im-immunisation and relatively smaller increases following oral immunisation. Substantial increases in the anti-O agglutination titres occurred in sheep immunised with the heat-killed vaccine by the im route. Direct and antiglobulin titres of both anti-O and anti-H antibodies increased significantly $(\mathrm{p}<0.001)$ by day 14 ( 7 days after the second intramuscular injection of the live mutant).

Skin responses. Results of the skin-hypersensitivity tests are presented in table III. It can be seen that sheep immunised with the live mutant strain
Table III. Hypersensitivity reactions in immunised and unimmunised sheep after intradermal injection with purified homologous lipopolysaccharide

\begin{tabular}{|c|c|c|c|c|}
\hline \multirow[b]{2}{*}{ Immunisation group } & \multicolumn{4}{|c|}{$\begin{array}{l}\text { Double skin-fold thickness }(\mathrm{mm}) \text { at } \\
\text { various times post-inoculation (mean } \\
\text { value } \pm \text { SEM) } \dagger\end{array}$} \\
\hline & $30 \mathrm{~min}$ & $24 \mathrm{~h}$ & $48 \mathrm{~h}$ & $72 \mathrm{~h}$ \\
\hline Live, oral & $\begin{array}{l}5 \cdot 25^{*} \pm \\
1.09\end{array}$ & $\begin{array}{l}3.05 \pm \\
1.04\end{array}$ & $\begin{array}{l}3.3 \pm \\
0.65\end{array}$ & $\begin{array}{l}1.5 \pm \\
0.87\end{array}$ \\
\hline Live, im & $\begin{array}{l}6.63^{* *} \pm \\
0.55\end{array}$ & $\begin{array}{l}8.9^{* * *} \pm \\
1.44\end{array}$ & $\begin{array}{l}5.95^{*} \\
0.92\end{array}$ & $\begin{array}{l}4.43^{*} \pm \\
1.03\end{array}$ \\
\hline Heat-killed, im & $\begin{array}{l}3 \cdot 5 \pm \\
1 \cdot 32\end{array}$ & $\begin{array}{l}5 \cdot 35 \pm \\
2 \cdot 23\end{array}$ & $\begin{array}{l}2 \cdot 65 \pm \\
1.07\end{array}$ & $\begin{array}{l}2.05 \pm \\
1.22\end{array}$ \\
\hline Unimmunised & $\begin{array}{l}1.86 \pm \\
0.42\end{array}$ & $\begin{array}{l}1.68 \pm \\
0.21\end{array}$ & $\begin{array}{l}1.98 \pm \\
0.58\end{array}$ & $\begin{array}{l}0.62 \pm \\
0.70\end{array}$ \\
\hline
\end{tabular}

† Values differing significantly from those recorded in the unimmunised animals are indicated; ${ }^{*} \mathrm{p}<0.05,{ }^{* *} \mathrm{p}<0.01,{ }^{* * *}$ $\mathrm{p}<0.001$.

SL1479 by the im route showed substantially greater swelling at all times after the injection of LPS than orally-immunised sheep. Significant immediatetype hypersensitivity reactions $(30 \mathrm{~min})$ were seen only in groups immunised with the live mutant; the

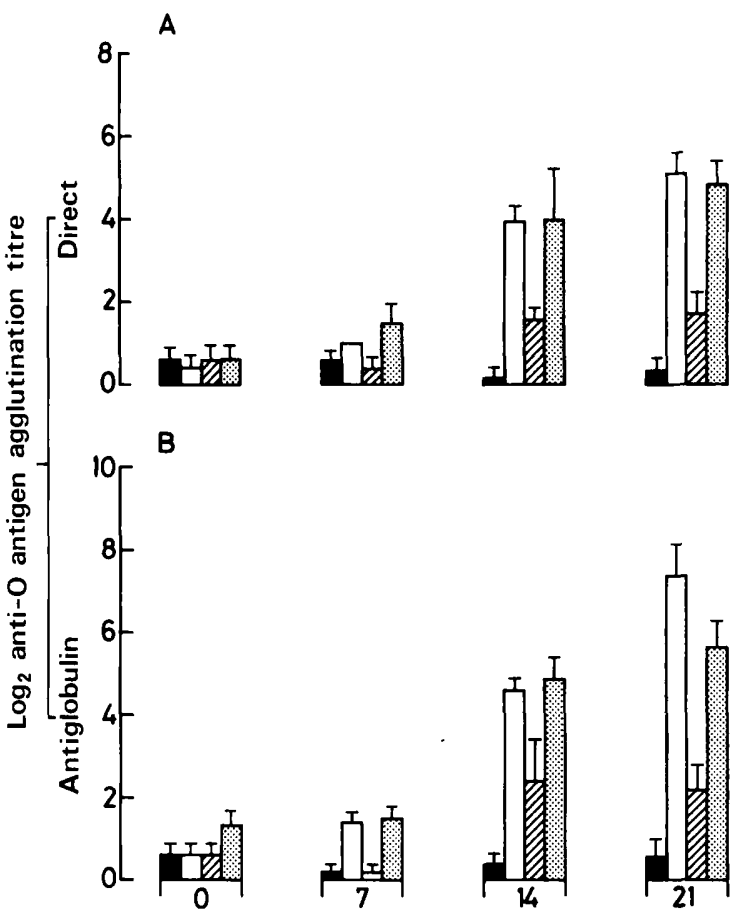

Day post-immunisation

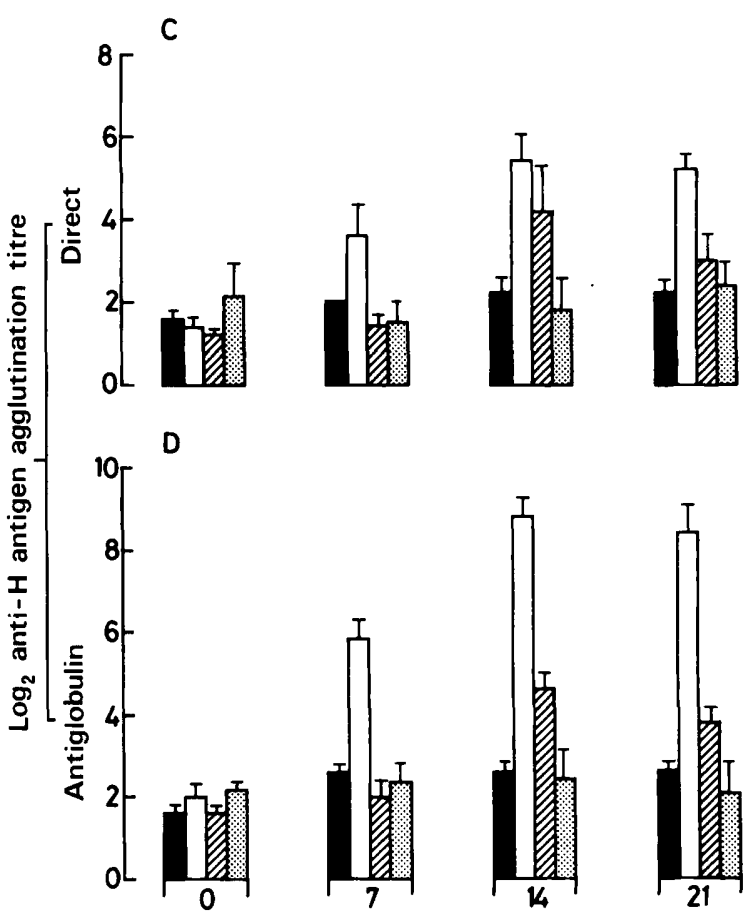

Day post-immunisation

Fig. 2. Titres of antibody against $\mathrm{O}-(\mathbf{A}, \mathbf{B})$ and $\mathrm{H}-(\mathbf{C},-\mathbf{D})$ antigens in serum of immunised and control sheep at various times after

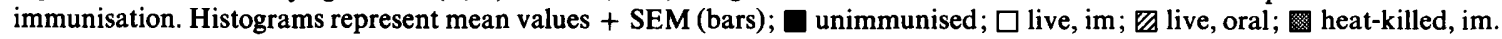


im group showed the larger reactions. The swellings at this time were oedematous, hot, red and painful. The swellings reached a maximum in the group immunised with the live mutant by the im route at $24 \mathrm{~h}$ but a large, indurated swelling was still present at $48-72 \mathrm{~h}$. This contrasted with the results in sheep immunised with the heat-killed vaccine by the intramuscular route, which showed distinct swelling at $24 \mathrm{~h}$, but this was substantially reduced in size by $48-72 \mathrm{~h}$.

\section{Discussion}

The observation of significant protection in mice immunised with the live $S$. typhimurium mutant SL1479 against challenge infection with a virulent bovine isolate (7328), but not an ovine isolate (12313), suggested that the challenge strains differed in their virulence. It was not clear whether the increased virulence of the ovine isolate was attributable to additional virulence characters not possessed by the bovine isolate, or was simply due to an amplified expression of the existing ones; the former explanation seems more likely because the LD50 of the ovine isolate was greater than that of the bovine isolate. The protection obtained in immunised mice when challenged with 10 LD50 was still significantly greater than that observed in mice immunised with three killed vaccines, and no significant increase in protection was achieved, even when the antigenic mass in the killed vaccines was increased. These results agree with some previous reports (Mitsuhashi et al., 1958; Ushiba et al., 1959; Smith, 1965; Collins et al., 1966) but contrast with those of others (Eisenstein and Angerman, 1978; Tato et al., 1979; Angerman and Eisenstein, 1980; Desiderio and Campbell, 1985). We do not consider it valid to compare the results reported by the latter investigators with those presented here for two major reasons. First, the CD-1 strain of mouse was used in their investigations; it had intermediate-to-high resistance to salmonellosis (Hormaeche, 1979). Second, the challenge infection was administered by the ip rather than the oral route. We consider the latter route to represent the most natural route of infection in salmonellosis. Collins and Carter (1972) compared the immunogenicity of heat-killed and living $S$. enteritidis vaccines by the oral route in CD-1 mice and reported that whereas oral immunisation of mice with a heat-killed vaccine delayed the systemic signs of gastrically-introduced salmonella infection by 1-2 days, immunisation with a living attenuated vaccine resulted in immunity as judged by the rapid removal of organisms from the liver, spleen and mesenteric lymph nodes, although the challenge organisms still persisted in the gut.

One possible reason for the superiority of the live vaccine could be due to the fact that the host is exposed to protective antigens for a longer period of time, thus allowing longer stimulation of the sites responsible for induction of immunity. We conducted an experiment (data not shown) in which mice were immunised with the heat-killed salmonella mutant, SL1479 $\left(1 \times 10^{5}\right.$ bacteria/mouse $)$ every day for 5 days. Exposure for periods longer than 5 days resulted in the development of ruffed coats and loss of body weight, perhaps because of the effect of endotoxins. These mice were challenged with 50 LD50 and 10 LD50 doses of the bovine and ovine isolates of $S$. typhimurium, but no significant protection was observed.

Therefore, it is clear from the data presented in this investigation that killed $S$. typhimurium organisms are inferior to the live mutant SL1479 as vaccines for protection against experimental mouse typhoid.

The manifestation of clinical salmonellosis in sheep as enteritis in this investigation contrasts with the results reported previously for S. typhimurium (Brown et al., 1976) in which the challenge organisms were recovered from practically all the internal organs, gut wall and contents, and various lymph nodes. A lack of systemic involvement was also reported by Hall et al. (1978) during their investigations on the pathogenesis of intra-ruminal infections of cows with $S$. dublin. The primary sites of bacterial penetration appeared to be the lower ileum and caecum. In these sites, the infection was considered to spread from the intestinal contents to the intestinal wall and to the associated lymph node. No spread to the liver and spleen occurred. In contrast, systemic involvement almost always occurs whenever the challenge dose of salmonellae is administered in such a way that the organisms come in contact with the oropharynx (De Jong and Ekdahl, 1965; McCaughey et al., 1971; Brown et al., 1976; Wray and Sojka, 1978; Smith et al., 1979). Although no direct experimental evidence is available, it is tempting to speculate that the oropharyngeal region may be involved in the process of systemic invasion.

In this investigation we found that when sheep were immunised with the live $S$. typhimurium mutant, SL1479, by the oral route, the organisms could be recovered in faeces for only 4 days postimmunisation. Essentially similar results were reported previously for calves immunised orally with the same live mutant (Robertsson et al., 1983). In contrast, the live mutant organism could not be 
cultured from the liver and spleen. Similar results were obtained when sheep were immunised by the intramuscular route.

Although killed vaccines have been reported to protect calves to varying degrees against experimentally-induced salmonellosis (Cameron and Fuls, 1976; Bairey, 1978; Smith et al., 1980; Aitken et al., 1982), surviving animals, in general, had moderate to severe manifestations of clinical salmonellosis. Recently, Robertsson et al. (1983) reported that calves immunised with an aromaticdependent $S$. typhimurium mutant, SL1479, by the oral route, were protected against experimentallyinduced acute salmonellosis, whereas those immunised with an heat-inactivated vaccine succumbed to the challenge infection. In our investigation, sheep immunised with the live, aromatic-dependent $S$. typhimurium mutant SL1479, by the im or the oral route and challenged with the virulent ovine isolate of $S$. typhimurium, were protected against the enteric form of salmonellosis. This is significant because the cellular and humoral immune mechanisms against Salmonella infection would have to operate at the intestinal mucosa and in the gut lumen. The generation of these immune mechanisms by oral immunisation is understandable (McGhee et al., 1984), but the mechanisms by which im immunisation provided the host with protective factors operative at the intestinal mucosal level are not known at present. It is clear, however, that there are marked differences in the antibody and skin reactions of sheep immunised by the two routes of immunisation.

Increases in the anti-O and anti-H agglutination

\section{REFERENCES}

Angerman C R, Eisenstein T K 1980 Correlation of the duration and magnitude of protection against Salmonella infection afforded by various vaccines with antibody titers. Infection and Immunity $27: 435-443$.

Aitken M M, Jones P W, Brown G T H 1982 Protection of cattle against experimentally induced salmonellosis by intradermal injection of heat-killed Salmonella dublin. Research in Veterinary Science 32:368-373.

Bairey M H 1978 Immunization of calves against salmonellosis. Journal of the American Veterinary Medical Association 173:610-613.

Brown D D, Ross J G, Smith A F G 1976 Experimental infections of sheep with Salmonella typhimurium. Research in Veterinary Science 21 :335-340.

Campbell D H, Garvey J S, Cremer N E, Sussdorf D H 1970 Methods in Immunology, 2nd edn. Benjamin, New York pp 128-131.

Cameron C M, Fuls W J P 1976 Immunization of mice and calves against Salmonella dublin with attenuated live and inactivated vaccines. Onderstepoort Journal of Veterinary Research 43: 31-37. titres were much larger in animals immunised by the im route than those in orally immunised animals. Assuming that the anti-O agglutination test measured antibodies to the LPS structure of Salmonella species, the finding that these antibodies, in sheep immunised with the heat-killed vaccine, were significantly higher than in those immunised with the live mutant by oral route were in agreement with results reported previously (Lindberg and Robertsson, 1983). The anti-H titres rose substantially only in the group immunised intramuscularly with the live mutant. Another significant aspect in which the results obtained in this investigation differed from those reported earlier was that sheep immunised by the oral route developed no delayedtype hypersensitivity, suggesting that the protection observed, may have been mediated by localised protective factors and possibly cell-mediated immune mechanisms operative at the intestinal mucus surface and in the gut lumen. A comparative study of the mechanisms of protection stimulated by the intramuscular or oral routes of immunisation is currently being performed.

We are very grateful to Mr J. Edwards, Ms. Suellen Tomkins and Mrs Helen Carpenter of McMaster Laboratory for their excellent technical assistance. We also acknowledge the competent assistance of $\mathrm{Mr} \mathrm{N}$. Catt and Mr. K. McKean during the sheep experiments. Finally, we are grateful to Mr C. Murray, Institute for Medical and Veterinary Science, for providing the clinical Salmonella isolates which were used as challenge strains in this investigation, and to Dr G. Eagleson for his advice on statistical analyses. Financial assistance for the work was provided from a CSIRO/University of Sydney Collaborative Research Fund.

Collins F M, Carter P B 1972 Comparative immunogenicity of heat-killed and living oral Salmonella vaccines. Infection and Immunity 6:451-458.

Collins F M, Mackaness G B, Blanden R V 1966 Infectionimmunity in experimental salmonellosis. Journal of Experimental Medicine 124:601-619.

Gell P G H, Coombs R R A 1968 Clinical Aspects of Immunology, 2nd edn. Blackwell, Oxford, p 19.

De Jong H, Ekdahl M O 1965 Salmonellosis in calves-the effect of dose rate and other factors on transmission. New Zealand Veterinary Journal 13:59-64.

Desiderio J V, Campbell S G 1985 Immunization against experimental murine salmonellosis with liposome-associated O-antigen. Infection and Immunity 48:658-663.

Eisenstein T K, Angerman C R 1978 Immunity to experimental Salmonella infection: studies on the protective capacity and immunogenicity of lipopolysaccharide, acetone-killed cells and ribosome-rich extracts of Salmonella typhimurium in $\mathrm{C} 3 \mathrm{H} / \mathrm{HeJ}$ and CD-1 mice. Journal of Immunology 121 : 1010 1014.

Germanier R 1972 Immunity in experimental salmonellosis III. Comparative immunization with viable and heat-inacti- 
vated cells of Salmonella typhimurium. Infection and Immunity 5:792-797.

Germanier R, Fürer E 1971 Immunity in experimental salmonellosis II. Basis for the avirulence and protective capacity of galE mutants of Salmonella typhimurium. Infection and Immunity 4:663-673.

Hall G A, Jones P W, Aitken M M 1978 The pathogenesis of experimental intra-ruminal infections of cows with Salmonella dublin. Journal of Comparative Pathology 88:409-417.

Hoiseth S K, Stocker B A D 1981 Aromatic-dependent Salmonella typhimurium are non-virulent and effective as live vaccines. Nature 291 : 238-239.

Hormaeche C E 1979 Natural resistance to Salmonella typhimurium in different inbred mouse strains. Immunology 37:311318.

Husband A J, McDowell G H 1978 Immunity to experimental enteritis in lambs vaccinated prenatally. Research in Veterinary Science 25: 343-349.

Ivanoff B, André C, Robert D, André F, Fontanges R 1980 Protective immunity and the cell-mediated immune response in mice following oral administration of an avirulent strain of Salmonella typhimurium. Annales de Microbiologie (Paris) 131 B: 153-161.

Jelinek P D, Robertson G M, Millar C 1982 Vaccination of sheep with live galE mutant of Salmonella typhimurium. Australian Veterinary Journal 59:31-32.

Kuusi N, Nurminen M, Saxen H, Mäkela P H 1981 Immunization with major outer membrane protein (porin) preparations in experimental murine salmonellosis: effect of lipopolysaccharide. Infection and Immunity 34:328-332.

Kuusi N, Nurminen M, Saxen H, Valtonen M, Makela P H 1979. Immunization with major outer membrane proteins in experimental salmonellosis of mice. Infection and Immunity $25: 857-862$.

Landy M 1953 Enhancement of the immunogenicity of typhoid vaccine by retention of the Vi antigen. American Journal of Hygiene 58 : 148-164.

Lindberg A A, Holme T 1972 Evaluation of some extraction methods for the preparation of bacterial lipopolysaccharides for structural analysis. Acta Pathologica et Microbiologica Scandinavica Section B, 80:751-759.

Lindberg A A, Robertsson J A 1983 Salmonella typhimurium infection in calves: cell-mediated and humoral immune reactions before and after challenge with live virulent bacteria in calves given live or inactivated vaccines. Infection and Immunity 41:751-757.

Litchfield J T, Wilcoxon F 1949 A simplified method of evaluating dose-effect experiments. Journal of Pharmacology and Experimental Therapeutics 96:99-113.

McCaughey W J, Kavanagh P J, McClelland T G 1971 Experimental Salmonella dublin infection in sheep. British Veterinary Journal 127:557-566.

McGhee J R et al. 1984 Mucosal immunoregulation: environmental lipopolysaccharide and GALT T lymphocytes regulate the $\operatorname{IgA}$ response. Microbiology and Immunology 28: $261-280$.

Mitsuhashi S, Kawakami M, Yamaguchi Y, Nagai M 1958 Studies on the experimental typhoid 1 . A comparative study of living and killed vaccines against the infection of mice with S.enteritidis. Japanese Journal of Experimental Medicine 28: $249-258$.

Murray C J 1984 Isolates of salmonella and Escherichia coli serotyped at the Salmonella Reference Laboratory in 1982 and 1983 from veterinary and human sources. Australian Veterinary Journal 61 : 273-274.

Prichard R K, Hennessy D R 1981 Effect of oesophageal groove closure on the pharmacokinetic behaviour and efficacy of oxfendazole in sheep. Research in Veterinary Science 30:2227.

Robertsson J A, Lindberg A A, Hoiseth S, Stocker B A D 1983 Salmonella typhimurium infection in calves: protection and survival of virulent challenge bacteria after immunization with live or inactivated vaccines. Infection and Immunity 41 : 742-750.

Smith B P, Habasha F, Reina-Guerra M, Hardy A J 1979 Bovine salmonellosis: experimental production and characterization of the disease in calves, using oral challenge with Salmonella typhimurium. American Journal of Veterinary Research 40:1510-1513.

Smith B P, Habasha F G, Reina-Guerra M, Hardy A J 1980 Immunization of calves against salmonellosis. American Journal of Veterinary Research 41 : 1947-1951.

Smith B P, Reina-Guerra M, Hoiseth S K, Stocker B A D, Habasha F, Johnson E, Merritt F 1984 Aromatic-dependent Salmonella typhimurium as modified live vaccines for calves. American Journal of Veterinary Research 45:59-66.

Smith H W 1965 The immunization of mice, calves and pigs against Salmonella dublin and Salmonella cholerai-suis infections. Journal of Hygiene 63: 117-135.

Svenson S B, Nurminen M, Lindberg A A 1979 Artificial Salmonella vaccines: $O$-antigenic oligosaccharide-protein conjugates induce protection against infection with Salmonella typhimurium. Infection and Immunity 25:863-872.

Tato P, Flisser A, Gavilanes M, Molinari J L 1979 Immunogenic complexes obtained from Salmonella typhimurium and Salmonella typhi $\mathrm{Ty} 2$ by the bacterial acetone powder method. Annales de Microbiologie (Institut Pasteur) 130A : 47-60.

Ushiba D, Saito K, Akiyama T, Nakano M, Sugiyama T, Shirono S 1959 Studies on experimental typhoid: bacterial multiplication and host cell response after infection with Salmonella enteritidis in mice immunized with live and killed vaccines. Japanese Journal of Microbiology 3:231242.

Westphal O, Jann K 1965 Bacterial lipopolysaccharides. Extraction with phenol-water and further applications of the procedure. In: Whistler R L et al. (eds) Methods in Carbohydrate Chemistry vol. 5. Academic Press, New York. pp 83-91.

Wray C, Sojka W J 1978 Experimental Salmonella typhimurium infection in calves. Research in Veterinary Science 25:139143.

Wray C, Sojka W J, Morris J A, Morgan W J B 1977 The immunization of mice and calves with galE mutants of Salmonella typhimurium. Journal of Hygiene 79:17-24. 